УДК 796

DOI https://doi.org/10.26661/2663-5925-2021-2-05

\title{
НАСТІЛЬНИЙ ТЕНІС ЯК ЗАСІБ ВИХОВАННЯ ФІЗИЧНИХ ЯКОСТЕЙ МОЛОДШИХ ШКОЛЯРІВ
}

\author{
Омельяненко Г. А. \\ кандидат педагогічних наук, \\ дочент кафедри теорії та методики фізичної культури і спорту \\ Запорізький національний університет \\ вул. Жуковського, 66, Запоріжжя, Украӥна \\ orcid.org/0000-0002-0490-4133 \\ znutmfkit@gmail.com
}

Соколова О. В.

кандидат наук з фізичного виховання і спорту, дочент, доиент кафедри теорії та методики фізичної культури і спорту

Запорізький національний університет

вул. Жуковського, 66, м. Запоріжжя, Украӥна

orcid.org/0000-0003-1062-0935

sokolova-znu@gmail.com

Деканов P.

аспірант кафедри теорії та методики фізичної культури і спорту

Запорізький національний університет

вул. Жуковського, 66, м. Запоріжжя, Украӥна

orcid.org/0000-0001-6201-4596

handball.survey@gmail.com

Польський С. Г.

викладач кафедри фізичної реабілітації та спортивної медицини, фізичного виховання та здоров'я

Запорізький державний медичний університет

просп. Маяковського, 26, Запоріжжя, Украӥна

orcid.org/0000-0002-5955-3510

lisgen2019@gmail.com

Ключові слова: фізична підготовленість, фізичне виховання, настільний теніс, молодиий шкільний вік.
Використання великої кількості різних форм організації занять фізичними вправами в системі шкільного фізичного виховання дозволяє найефективніше задовольняти потребу учнів в руховій активності і вирішувати завдання фізичного виховання школярів на різних етапах вікового розвитку їхнього організму. Мета дослідження обгрунтування ефективність впливу занять із настільного тенісу на розвиток фізичних якостей у дітей молодшого шкільного віку. Об'єкт дослідження - процес фізичного виховання дітей молодшого шкільного віку. Суб'єкт дослідження - учні молодшого шкільного віку. Методи дослідження: теоретичний аналіз і узагальнення науково-методичних джерел за темою дослідження, педагогічні спостереження, педагогічний експеримент, методи визначення рівня розвитку фізичних якостей, методи математичної статистики. Результати дослідження. Визначено, що заняття 3 настільного тенісу мають значний вплив на розвиток 
фізичних якостей дітей молодшого шкільного віку. Так, аналіз динаміки показників фізичних якостей учнів контрольної групи виявив істотні відмінності лише за показниками тестів «Вправи на поєднання рухів» $(\mathrm{P}<0,05)$ і «Ходьба по прямій лінії після 5 обертів» $(\mathrm{P}<0,05)$; в учнів експериментальної групи засвідчив достовірні відмінності за кожним із показників: «Стрибок у довжину з місця, см» $(\mathrm{P}<0,05)$; «Біг 300 м, хв» $(\mathrm{P}<0,001)$; «Біг 30 м, с» $(\mathrm{P}<0,001)$; «Нахил тулуба, см» $(\mathrm{P}<0,001)$; «Підтягування у змішаному висі на канаті, рази» $(\mathrm{P}<0,05)$; «Човниковий біг $4 \times 9$ м, с» $(\mathrm{P}<0,05)$; «Вправи на поєднання рухів, кількість помилок» $(\mathrm{P}<0,01)$; «Час збереження стійкого положення, с» $(\mathrm{P}<0,001)$; «Ходьба по прямій лінії після 5 обертів, помилка в см» $(\mathrm{P}<0,001)$. Висновки. Упровадження настільного тенісу засвідчило свою ефективність, що підтверджено приростами відповідних показників.

\section{TABLE TENNIS AS A MEANS OF EDUCATION OF PHYSICAL QUALITIES OF JUNIOR SCHOOLCHILDREN}

Omelianenko H. A.

Ph. D. in Pedagogics, Associate Professor,

Associate Professor at the Department of Theory and Methods of Physical Culture and Sports

Zaporizhzhia National University

Zhukovskoho str., 66, Zaporizhzhia, Ukraine

orcid.org/0000-0002-0490-4133

znutmfkit@gmail.com

Sokolova O. V.

Ph. D., Associate Professor,

Associate Professor at the Department of Theory and Methods

of Physical Culture and Sports

Zaporizhzhia National University

Zhukovskoho str., 66, Zaporizhzhia, Ukraine

orcid.org/0000-0003-1062-0935

sokolova-znu@gmail.com

Dekanov R.

Postgraduate Student at the Department of Theory and Methods of Physical Culture and Sports

Zaporizhzhia National University

Zhukovskoho str., 66, Zaporizhzhia, Ukraine

orcid.org/0000-0001-6201-4596

handball.survey@gmail.com

\section{Polskyi S. H.}

Lecturer at the Department of Physical Rehabilitation, Sports Medicine,

Physical Education and Health

Zaporizhzhia State Medical University University

Mayakovsky ave, 26, Zaporizhzhia, Ukraine

orcid.org/0000-0002-5955-3510

lisgen2019@gmail.com 
Key words: physical preparedness, physical education, table tennis, junior school age.
The necessary to change substantially the content of the physical education classes, making them more interesting, to use new specific means of physical education for the development of physical abilities and the formation of motional skills, to teach children independent physical exercising. Schools are ideal settings for the promotion of physical activitysince all children can be reached. Unlike organized sports game, children's play, consistent with the rules, knows no formal criteria of membership. The purpose of this study is to substantiate the effectiveness of the impact of tennis on the development of physical qualities in children of primary school age. The objective of the research - is the process of physical education of children of primary school age. Subject of the research - dynamics of indicators of physical fitness of physical fitness. Research subject - is primary school students. Research methods: analysis and summary of the literature on the topic of the research; analysis of documentary materials; pedagogical experiment; pedagogical observations; pedagogical testing (indicators of physical fitness); methods of mathematical statistics (used to process empirical data at the stages of the study). Results of the research. It is determined that table tennis classes have a significant impact on the development of physical qualities of children of primary school age. Thus, the analysis of the dynamics of indicators of physical qualities of students in the control group revealed significant differences only in the indicators of tests "Exercises for the combination of movements" $(\mathrm{P}<0,05)$ and "Walking in a straight line after 5 turns" $(\mathrm{P}<0,05)$; in students of the experimental group showed significant differences in each of the indicators: "Long jump from the place, $\mathrm{cm}$ " $(\mathrm{P}<0,05)$; "Running $300 \mathrm{~m}$, min" (P<0,001); "Running $30 \mathrm{~m}$, s" $(\mathrm{P}<0,001)$; "Tilt of the torso, cm" $(\mathrm{P}<0,001)$; "Pull-up in the mixed suspension on the rope, times" $(\mathrm{P}<0,05)$; "Shuttle running $4 \times 9 \mathrm{~m}$, s" $(\mathrm{P}<0,05)$; "Exercises for the combination of movements, the number of errors" $(\mathrm{P}<0,01)$; "Stability time, $\mathrm{s}$ " $(\mathrm{P}<0,001)$; "Walking in a straight line after 5 turns, error in $\mathrm{cm}$ " $(\mathrm{P}<0,001)$. Conclusions. It was proved that the table tennis a positive effect on the performance of the physical condition of junior school age.
Вступ. Фізична культура розглядається як найважливіший, іноді вирішальний чинник у зміцненні здоров'я молодого покоління і подоланні ним несприятливих умов довкілля. Важливим завданням фізичного виховання є зміцнення здоров'я людини як складової частини повноцінного розумового і морального розвитку особистості ще з раннього дитинства. Сьогодні стають звичними тривожні дані про систематичне погіршення стану здоров'я, зниження працездатності i рівня фізичної підготовленості дітей молодшого шкільного віку [2; 4].

Ефективним способом удосконалення системи фізичного виховання є організація гурткової роботи 3 тенісу [5]. Настільний теніс належить до числа найпопулярніших спортивних ігор. Нескладні правила цієї захоплюючої гри, доступний інвентар роблять настільний теніс одним із найулюбленіших і доступних для систематичних занять видом спорту. Це, можна сказати, ідеальна гра для людей будь-яких професій і різного рівня стану здоров'я. Настільний теніс також є прекрасним засобом активного відпочинку, який приносить величезне задоволення і бадьорість $[1 ; 3]$.
Мета роботи - обгрунтувати ефективність впливу занять із настільного тенісу на розвиток фізичних якостей у дітей молодшого шкільного віку.

Організація дослідження. В експерименті брали участь 20 учнів 4-го класу, 10 із яких увійшли в експериментальну групу, а 10 - у контрольну. В експериментальній групі проводилися заняття в гуртку 3 настільного тенісу тричі на тиждень тривалістю 1 година. На початку експерименту за допомогою тестів були визначені рівні рухових здібностей школярів. У кінці експерименту було проведено повторне визначення рівня рухових здібностей дітей контрольної й експериментальної груп. Усі школярі, за даними медичного огляду, були віднесені до основної медичної групи.

Для вирішення поставлених завдань у роботі використовувалися такі методи визначення рівня розвитку фізичних якостей: стрибок у довжину 3 місця, см; біг 300 м, с; біг 30 м, с; нахил тулуба, см; підтягування у змішаному висі на канаті, рази; човниковий біг $4 \times 9$ м, с; вправи на поєднання, кількість помилок; час збереження стійкого положення, с; ходьба по прямій лінії після 5 обертів, помилка в см. 
В обробці експериментальних даних застосовувалися традиційні методи математичної статистики, зокрема метод середніх величин, вибірковий метод і ряди динаміки. Розраховувалися середнє арифметичне значення, середнє квадратичне відхилення, відносний приріст, критерій вірогідності Ст'юдента (за рівня не менше $\mathrm{p}<0,05)$. Експериментальний матеріал опрацьовано $з$ використанням пакетів статистичних програм Statistika 7.0 та Exel.

Виклад основного матеріалу дослідження. На початку експерименту за допомогою контрольного тестування визначені показники фізичних якостей в учнів контрольної й експериментальної груп, які не виявили за жодним із показників. За результатами повторного тестування фізичних якостей учнів контрольної й експериментальної груп наприкінці дослідження виявлено таке: за тестом «Стрибок у довжину 3 місця, см» показники учнів контрольної групи становили $135,50 \pm$ $1,50 \mathrm{~cm}$, а експериментальної групи $-140,80 \pm$ 1,30 с $(\mathrm{t}=2,67 ; \mathrm{P}<0,05)$; у тесті «Біг 300 м, хв» показники учнів контрольної групи становили $1,40 \pm 0,03$ хв, а експериментальної групи - 1,27 \pm 0,03 хв $(\mathrm{t}=3,06 ; \mathrm{P}<0,01)$; за тестом «Біг $30 \mathrm{M}, \mathrm{c}$ » показники учнів контрольної групи становили $6,28 \pm 0,08$ с, а експериментальної групи $-5,98 \pm$ $0,06 \mathrm{c}(\mathrm{t}=3,00 ; \mathrm{P}<0,01) ;$ у тесті «Нахил тулуба, см» показники учнів контрольної групи становили $3,90 \pm 0,20$ см, а експериментальної групи $-4,90 \pm$ $0,20$ см ( $\mathrm{t}=3,54 ; \mathrm{P}<0,01)$; за тестом «Підтягування у змішаному висі на канаті, рази» показники учнів контрольної групи становили $12,90 \pm 0,50$, а експериментальної групи - 14,90 $\pm 0,50(\mathrm{t}=2,83$; $\mathrm{P}<0,05)$; у тесті «Човниковий біг $4 \times 9$ м, с» показники учнів контрольної групи становили $12,34 \pm$ $0,20 \mathrm{c}$, а експериментальної групи $-11,70 \pm 0,10 \mathrm{c}$ $(\mathrm{t}=2,86 ; \mathrm{P}<0,05) ;$ у тесті «Вправи на поєднання рухів, кількість помилок» показники учнів контрольної групи становили 1,69 $\pm 0,10$ помилок, а експериментальної групи $-1,20 \pm 0,10$ помилок $(\mathrm{t}=3,46 ; \mathrm{P}<0,01)$; у тесті «Час збереження стійкого положення, с» показники учнів контрольної групи становили $5,40 \pm 0,30 \mathrm{c}$, а експериментальної групи $-6,70 \pm 0,20 \mathrm{c}(\mathrm{t}=3,61 ; \mathrm{P}<0,01)$; за результатами тесту «Ходьба по прямій лінії після 5 обертів, помилка в см» показники учнів контрольної групи становили $83,50 \pm 2,00 \mathrm{c}$, а експериментальної групи $-75,30 \pm 2,00 \mathrm{c}(\mathrm{t}=2,90 ; \mathrm{P}<0,01)$.

Отже, аналіз динаміки показників фізичних якостей учнів контрольної групи виявив істотні відмінності лише за даними тестів «Вправи на поєднання рухів» $(\mathrm{P}<0,05)$ i «Ходьба по прямій лінії після 5 обертів» $(\mathrm{P}<0,05)$. Аналіз динаміки показників фізичних якостей учнів експериментальної групи засвідчив достовірні відмінності

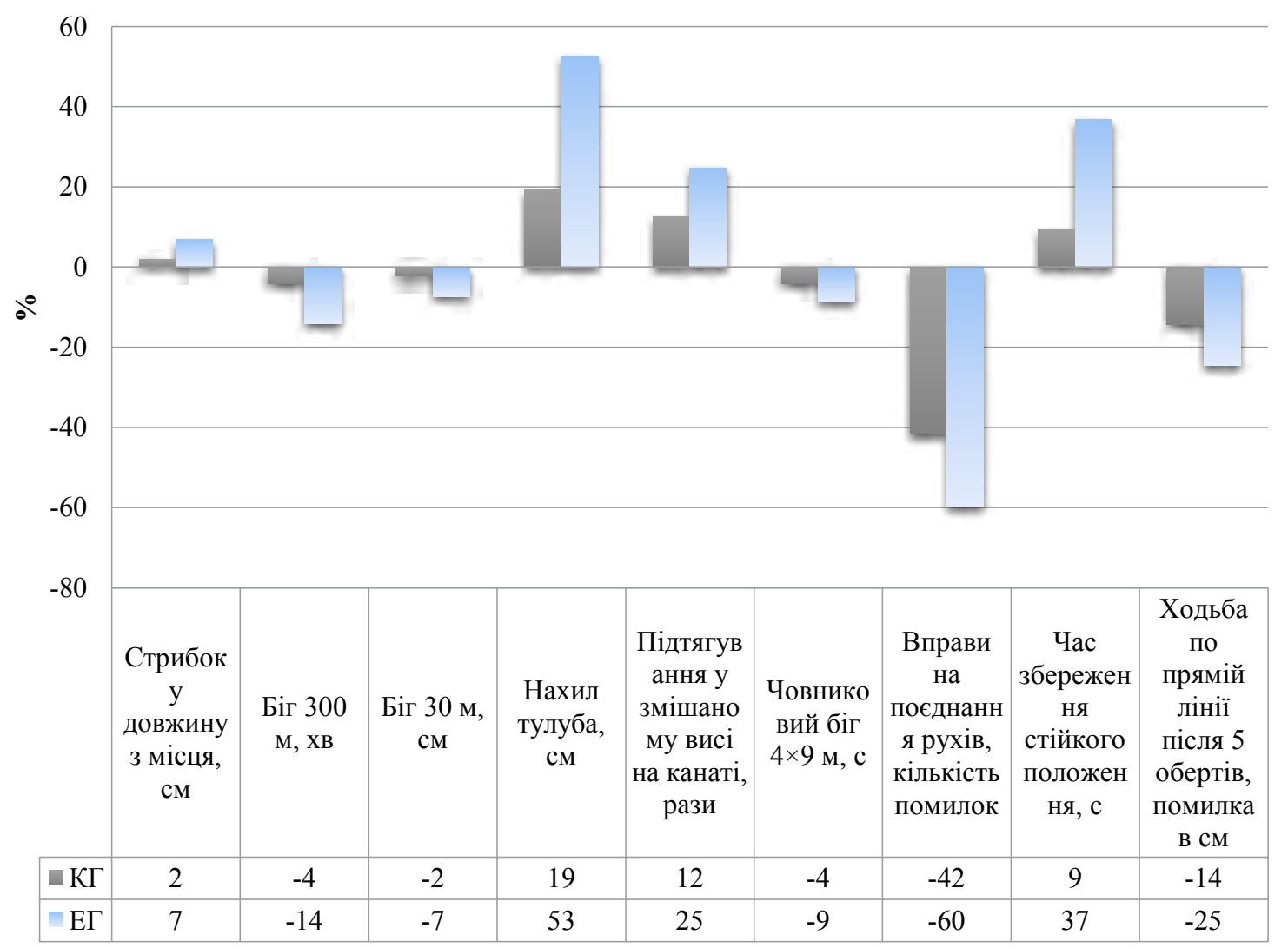

Рис. 1. Відносний приріст показників фізичних якостей учнів 
за кожним iз показників. Крім того, значення абсолютного та відносного приросту показників фізичних якостей в учнів експериментальної та контрольної груп показав, що відносні показники в експериментальній групі значно вищі, ніж у контрольній (рис. 1). Найбільший відносний приріст зафіксовано серед показників «Вправи на поєднання рухів, кількість помилок» (-59,73\%) та «Нахил тулуба, см» $(52,65 \%)$ в учнів експериментальної групи; найменший відносний приріст зафіксовано серед показників «Біг $30 \mathrm{M}$, с» $(-2,00 \%)$ в учнів контрольної групи.

Отже, на підставі проведеного дослідження можна зробити висновок, що настільний теніс позитивно впливає на показники фізичні якості школярів молодших класів.

Висновки. Аналіз спеціальної науково-методичної літератури засвідчив, що фізична культура у шкільному віці має особливо велике значення для формування необхідних у житті рухових умінь, навичок, опанування основ їх практичного використання в різноманітних умовах рухової діяльності та в підвищенні працездатності. Відзначено, що порівняно із середнім та старшим шкільним віком фізичні навантаження $є$ найефективнішими в молодших класах, а найістотніші зміни в розвитку фізичних властивостей відбуваються в 6-12 років. Отже, за умови врахування вікових особливостей розвитку дітей можна вдало та спрямовано розвивати основні фізичні здібності в дітей молодшого шкільного віку шляхом урізноманітнення фізичних вправ, яке може бути реалізованим включенням до програми спортивних ігор, зокрема настільного тенісу.

Результати показників фізичних якостей молодших школярів в експериментальній групі під впливом занять у гуртку з настільного тенісу достовірно виросли щодо контрольної.

\section{ЛІТЕРАТУРА}

1. Асєєва Я., Шевченко О. Взаємозв'язок психофізіологічних показників та технічної підготовленості у спортсменів з настільного тенісу на етапі попередньої базової підготовки. Слобожсанський науково-спортивний вісник. 2019. №. 6К. С. 5-9.

2. Экспериментальное исследование свойств игрового внимания и качеств мышления у спортсменов, занимающихся настольным теннисом / В. Бурцев и др. Проблемы современного педагогического образования. 2017. № 56-6. С. 31-39.

3. Мальчевская Н. Настольный теннис для всех. Физическая культура, спорт и здоровье. 2016. №. 27. C. 59.

4. Попова Н. Популяризация настольного тенниса: здоровьесберегающий и адаптивно-акмепедагогический компоненты. Наука и молодежь: проблемы, поиски, решения. 2019. С. 275-279.

5. Чуева И. Физическое воспитание младших школьников средствами настольного тенниса в условиях трех уроков физкультуры в общеобразовательной школе. Физическая культура: воспитание, образование, тренировка. 2006. №. 2. С. 42-44.

\section{REFERENCES}

1. Asyeyeva Ya., Shevchenko O. (2019). Vzayemozv'yazok psykhofiziolohichnykh pokaznykiv ta tekhnichnoyi pidhotovlenosti u sportsmeniv z nastil'noho tenisu na etapi poperedn'oyi bazovoyi pidhotovky [The relationship of psychophysiological indicators to the indicators of level of technical-tactical preparedness among tennis players at the stage of the previous basic preparation]. Slobozhans 'kyy naukovo-sportyvnyy visnyk. № 6K. S. 5-9.

2. Burtsev V.A. et al. (2017). Eksperimental'noye issledovaniye svoystv igrovogo vnimaniya i kachestv myshleniya u sportsmenov, zanimayushchikhsya nastol'nym tennisom. [Pilot study of properties of game attention and qualities of thinking at the athletes playing table tennis]. Problemy sovremennogo pedagogicheskogo obrazovaniya. № 56-6. S. 31-39.

3. Mal'chevskaya N.N. (2016). Nastol'nyy tennis dlya vsekh [Table tennis for everyone]. Fizicheskaya kul'tura, sport i zdorov'ye. № 27. S. 59.

4. Popova N.V. (2019). Populyarizatsiya nastol'nogo tennisa: zdorov'yesberegayushchiy i adaptivnoakmepedagogicheskiy komponenty [Popularization of table tennis: health-preserving and adaptiveacmepedagogical components]. Nauka i molodezh': problemy, poiski, resheniya. S. 275-279.

5. Chuyeva I.A. (2006). Fizicheskoye vospitaniye mladshikh shkol'nikov sredstvami nastol'nogo tennisa $\mathrm{v}$ usloviyakh trekh urokov fizkul'tury $\mathrm{v}$ obshcheobrazovatel'noy shkole [Physical education of junior schoolchildren by means of table tennis in the conditions of three lessons of physical education in a comprehensive school]. Fizicheskaya kul tura: vospitaniye, obrazovaniye, trenirovka. 2006. № 2. S. 42-44. 